\title{
The 67-kD Elastin/Laminin-binding Protein Is Related to an Enzymatically Inactive, Alternatively Spliced Form of $\beta$-Galactosidase
}

\author{
Aleksander Hinek, *" Marlene Rabinovitch, *" Fred Keeley, "Yuko Okamura-Oho, ${ }^{*}$ and John Callahan"" \\ ${ }^{*}$ Division of Cardiovascular Research and ${ }^{\ddagger}$ Division of Neurosciences, Research Institute, The Hospital for Sick Children, Toronto; and \\ Departments of ${ }^{\S}$ Pathology, "Clinical Biochemistry, and 'Biochemistry, University of Toronto, Ontario, Canada M5G $1 X 8$
}

\begin{abstract}
We and others have previously shown that a 67-kD cell surface elastin/laminin-binding protein (EBP) is responsible for cell adhesion to elastin and laminin and for mediating the process of elastin fiber assembly, but the nature of this protein was unknown. In this report we provide evidence that a $67-\mathrm{kD}$ catalytically inactive form of $\boldsymbol{\beta}$-galactosidase produced by alternative splicing demonstrates immunological and functional similarity and sequence homology to the 67-kD EBP, suggesting that the two might be the same. Antibody prepared to a synthetic peptide, $\boldsymbol{N}$-Ac-GSPSAQDEASPL, corresponding to a frameshift-generated sequence unique to the alternatively spliced form of human $\beta$-galactosidase, also recognized sheep EBP both on Western blotting and in aortic tissue. Furthermore, this synthetic peptide (S-GAL) binds to elastin and laminin, but not to fibronectin, collagen I, or collagen III. Moreover, both tropoelastin and laminin which bind to S-GAL peptide affinity columns can be specifically eluted from them with an excess of free S-GAL peptides. In addition, sequence homology among this splice variant of human $\beta$-galactosidase, sheep EBP, and $\mathrm{NH}_{2}$-terminal sequences of some elastases suggests that these proteins share a common ligand-binding motif that has not been previously recognized. (J. Clin. Invest. 1993. 91:1198-1205.) Key words: elastin receptor • laminin receptor • elastin assembly • extracellular matrix $\bullet$ vascular disease
\end{abstract}

\section{Introduction}

The process of elastic fiber assembly is mediated by a nonintegrin cell surface receptor complex consisting of three protein subunits (1). Two of these subunits are integral membrane proteins that allow a transmembrane link between the extracellular ligand and the cytoskeleton. The third subunit is a $67-\mathrm{kD}$ cell surface protein which binds via three separate sites to VGVAPG, a hydrophobic sequence of elastin, to the integral membrane subunits, and to $\beta$-galactosugars. The latter prop-

Address correspondence to Dr. Aleksander Hinek, Division of Cardiovascular Research, Research Institute, The Hospital for Sick Children, 555 University Avenue, Toronto, Ontario, Canada M5G 1 X8.

Received for publication 19 June 1992 and in revised form 3 November 1992.

J. Clin. Invest.

(c) The American Society for Clinical Investigation, Inc.

$0021-9738 / 93 / 03 / 1198 / 08 \quad \$ 2.00$

Volume 91, March 1993, 1198-1205 erty relates the $67-\mathrm{kD}$ elastin-binding protein $(\mathrm{EBP})^{1}$ to a family of S-type, $\mathrm{Ca}^{2+}$-independent, $\beta$-galactoside-specific lectins (1-3). Binding of galactosugars to the lectin site of EBP lowers its affinity both for elastin and for the cell-binding site, resulting in the release of elastin and the dissociation of the $67-\mathrm{kD}$ subunit from the cell membrane. Immunolocalization of EBP to the extracellular elastic matrix suggests that at least some of this protein is subsequently incorporated into the elastic fiber (4). Binding of newly synthesized elastin to EBP and its release under the influence of galactosugars appears to play a key role in directing and coordinating the extracellular assembly of elastic fibers (4). Our previous studies have shown that chondroitin sulfate and dermatan sulfate, $N$-acetyl galactosamine-containing glycosaminoglycans, will detach EBP from aortic smooth muscle cell surfaces and interfere with the process of elastin fiber assembly (4). The EBP also shares a common molecular weight, immunological and affinity properties with a receptor interacting with LGTIPG, a hydrophobic sequence in domain $\mathrm{V}$ of the $\mathrm{B} 1$ chain of laminin $(5,6)$, prompting suggestions that these two receptors may in fact be the same protein.

Recently we made the observation that an antibody to human placental $\beta$-galactosidase localized to aortic smooth muscle cell surfaces and to the extracellular elastic matrix in sections of aortic tissue, with a distribution similar to that of the EBP. Beta-galactosidase is an enzyme that hydrolyzes $\beta$-linked terminal galactosyl residues from a variety of substrates, including glycoproteins, glycolipids, and glycosaminoglycans (7). The active enzyme has a molecular weight of $64 \mathrm{kD}$ and is normally compartmentalized to lysosomes. However, an enzymatically inactive form of this protein generated from an alternatively spliced mRNA has recently been described by Morreau et al. (8). This form of $\beta$-galactosidase arises through the splicing out of two noncontiguous protein-encoding regions in such a way that the first deletion introduces a frame shift which is restored by the deletion of the second region (Fig. 1 , upper panel). The net result of these deletions is a shortened protein with the introduction of a 32-amino acid sequence unique to the alternately spliced form of the protein. As a result of posttranslational modification, the final molecular weight of this enzymatically inactive splice variant of $\beta$-galactosidase is $67-68 \mathrm{kD}$. It is released to the cell surface, but has no known biological function. In this report we present evidence based on immunological and functional similarity, and sequence homol-

1. Abbreviations used in this paper: EBP, elastin/laminin-binding protein; GAM, goat anti-mouse; GAR, goat anti-rabbit; HRP, horseradish peroxidase; S-Gal, $N$-acetyl-GSPSAQDEASPL oligopeptide. 
ogy that this alternately spliced form of $\beta$-galactosidase is related to the $67-\mathrm{kD}$ elastin/laminin binding protein. Moreover, we have identified a new elastin binding motif in the alternatively spliced form of $\beta$-galactosidase produced as a result of the frame shift. This elastin binding motif is also found in numerous elastases.

\section{Methods}

\section{Materials}

Chemicals and reagents were obtained as follows: kappa-elastin, insoluble elastin, bovine tropoelastin, human leukocyte elastase, and antibody to tropoelastin were purchased from Elastin Products (Pacific, MO). Human plasma fibronectin, laminin from Engelbret HolmSwarm tumor, collagen I, collagen III, porcine pancreatic elastase, 4methylumbelliferyl- $\beta$-galactoside, $\gamma$-D-galactonolactone, lactose, ovalbumin, maleimidobenzoyl- $N$-hydroxysuccinimide, dimethylformamide, proteinase inhibitors, Protein A Sepharose, all reagent grade chemicals, and antibodies to fibronectin, laminin and collagen type I and III were purchased from Sigma Immunochemicals (St. Louis, MO). Monoclonal antibody (anti-EBP) to the elastin-binding protein was a gift from Dr. R. P. Mecham, Washington University, St. Louis, MO. Species and type-specific secondary antibodies, goat anti-mouse horseradish peroxidase-conjugated (GAM-HRP) and goat anti-rabbit (GAR) HRP used in Western blotting were supplied by Boehringer Mannheim Biochemicals (Indianapolis, IN). Goat anti-rabbit and goat anti-mouse secondary antibodies conjugated with $10-\mathrm{nm}$ gold particles for immunoelectron microscopy were obtained from Janssen Life Science Products (Piscataway, NJ). Ultrosyn-D resin, Sepharose 4B were from Pharmacia Inc. (Uppsala, Sweden). Nitrocellulose, Immobilon P, Affi-gel 10, Affi-gel Protein A, and all reagents for SDS polyacrylamide gel electrophoresis were purchased from Bio-Rad Laboratories (Richmond, CA).

\section{Production of antipeptide antibodies}

Anti-S-GAL-antibody to the N-Ac-GSPSAQDEASPL synthetic peptide. The $N$-acetyl-GSPSAQDEASPL oligopeptide (S-GAL), corresponding to a portion of the protein sequence unique to the alternatively spliced form of human $\beta$-galactosidase (Fig. 1) was synthesized using a BioLynx automated oligopeptide synthesizer (Pharmacia Inc.) (9), chemically coupled to the Ultrasyn beads via the terminal leucine carboxyl group, and used as an antigen. Briefly, $10 \mathrm{mg}$ of this S-GALconjugated resin (containing $1 \mathrm{mg}$ of S-GAL oligopeptide) was suspended in $0.25 \mathrm{ml}$ saline, mixed with incomplete Freund's adjuvant $(0.25 \mathrm{ml})$, and sonicated. The rabbit was injected subcutaneously at various sites a total of five times over the course of $3 \mathrm{mo}$, and finally exsanguinated under nembutal anesthesia. IgG was purified from serum by chromatography on Protein A-Sepharose CL4B according to standard methods (10). To affinity purify the specific antipeptide antibody, the purified IgG in phosphate-buffered saline ( $\mathrm{pH} 7.4$ ) was percolated through a small column of Ultrasyn beads ( $50-\mathrm{mg}$ beads) containing the immobilized S-GAL oligopeptide $(4.7 \mathrm{mg})$. The column was washed exhaustively with phosphate-buffered saline ( $\mathrm{pH} 7.4)$ and bound IgG was eluted with $1 \mathrm{M}$ glycine, $0.5 \mathrm{M} \mathrm{KCl}, \mathrm{pH} 2.5$. The $\mathrm{pH}$ was then quickly adjusted to 7.0 by the addition of saturated $\mathrm{Na}_{2} \mathrm{CO}_{3}$. This affinity purified antibody (designated as anti-S-GAL) was then dialyzed overnight against phosphate-buffered saline ( $\mathrm{pH} 7.4)$, and aliquoted.

\section{Anti-C-GAL- antibody to N-Ac-CPPQKNKDSWLDHV synthetic peptide}

The oligopeptide, $N$-Ac-(C)PPQKNKDSWLDHV, (C-GAL) corresponding to the $\mathrm{COOH}$-terminal sequence of $\beta$-galactosidase was also synthesized on a BioLynx Automated Peptide Synthesizer (Pharmacia) (9) such that the carboxyl group of the terminal valine was free and a cysteine residue was added at the $\mathrm{NH}_{2}$ terminus. An ovalbumin-C- deletion 1

79 AIQTYVPWNF HEPWPGQYQF SEDHDVEYELRLAHELGLLVI LRPGPY ICAEWEMGGL 79 AIQT - - - - - - - - - - - - - - - - - -

139 PAWLLEKESILLRS SDPDYLAAVDKWLGVLLPKMKF LLYQNGGPVITVQVENEYGSY 83 - $-\ldots \ldots$ - - - - IPGSCGQVVGSPSAQDEASPLSEWRASYNSAG - - .

deletion 2

193 FACDFDYLRFLQKRFRHHLGDDVVLFTTDGAHKTFLKCGALQGLYTTVDFGTGSNIT $115-\ldots-\ldots-\ldots-\ldots-\ldots-\ldots-\ldots-\ldots-\ldots$

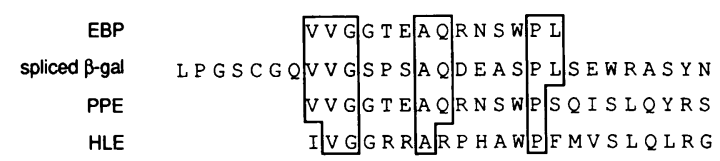

Figure 1. (Upper panel) Amino acid sequence of enzymatically active $\beta$-galactosidase (top sequence) compared to that of the $67-\mathrm{kD}$ inactive splice variant (bottom sequence) (8). Deletion of the first segment introduces a -1 frame shift producing the unique peptide sequence in the splice variant shown in bold type. The second deletion restores the reading frame, and the balance of the sequence is identical in the two proteins. A synthetic peptide corresponding to the underlined sequence in the splice variant (S-GAL) was synthesized and an antibody (anti-S-GAL) was prepared as described. (Lower panel) Comparisons of the sequence determined for the $\mathrm{CNBr}$ fragment of purified sheep elastin-binding protein $(E B P)$ with the region of sequence unique to the splice variant of $\beta$-galactosidase. 7 of 14 residues are identical, and a further three substitutions have no effect on net charge. $\mathrm{NH}_{2}$-terminal sequences of porcine pancreatic elastase ( $\left.P P E\right)$ (17) and human leukocyte elastase ( $H L E)$ (19) are also included for comparison. Regions of sequence identity between these proteins and the splice variant of $\beta$-galactosidase are boxed.

GAL peptide conjugate was then synthesized by a two step chemical coupling method using maleimidobenzoyl- $N$-hydroxysuccinimide ester (11) and used as the antigen for subcutaneous immunization of the rabbit (as described above). Crude IgG fraction was isolated on Protein A-Sepharose as described above and then affinity purified on a C-GAL oligopeptide-Sepharose $4 \mathrm{~B}$ column made according to the manufacturer's instructions and equilibrated in phosphate-buffered saline $\mathrm{(pH}$ 7.4). The bound IgG was eluted with $1 \mathrm{M}$ glycine, $0.5 \mathrm{M} \mathrm{KCl}, \mathrm{pH} 2.5$, dialyzed overnight against phosphate-buffered saline $(\mathrm{pH} 7.4)$ and used for Western immunoblots. Specificity of this antibody was proven by its reactivity with the precursor of $\beta$-galactosidase produced by permanently transfected Chinese hamster ovary cells and by human skin fibroblasts. For both antibodies preimmune sera were used as a negative control.

\section{Immunoelectron microscopy}

For immunoelectron microscopy, we used a postembedding method previously described (1). Antibodies were: anti-EBP, a monoclonal antibody to elastin-binding protein (12), anti-GAL, a polyclonal antibody to human placental $\beta$-galactosidase (13), and anti-S-GAL, an affinity-purified polyclonal antibody. Thin sections were placed on nickel grids, blocked with $1 \%$ BSA, and $0.5 \%$ Tween 20 in TBS, and reacted with the antibodies $(2 \mathrm{mg} / \mathrm{ml}$, diluted 1:200). The immune reaction was visualized with the appropriate GAR or GAM secondary antibody conjugated with $10-\mathrm{nm}$ gold particles. Sections were then stained with uranyl acetate and lead citrate. In all immunostaining procedures controls involved substitution of nonimmune ascites fluid or normal rabbit serum for the primary antibody. Further controls used primary antibodies after preabsorption to elastin or EBP affinity columns (4). 


\section{Affinity chromatography of $\beta$-galactosidase on elastin}

Human placental extract was prepared as described previously (13, 14 ). This preparation, containing both $64-\mathrm{kD}$ and $67-\mathrm{kD}$ forms of $\beta$-galactosidase and their higher molecular weight precursors, was dis-

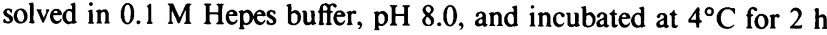
either with insoluble elastin purified from bovine ligamentum nuchae or with kappa-elastin fixed to Affi-gel 10 as described previously $(1,4)$. Affinity columns were washed well with buffer, and bound proteins eluted with $0.1 \mathrm{M}$ lactose or $0.1 \mathrm{M} \gamma$-D-galactonolactone in $0.1 \mathrm{M}$ Hepes buffer, pH 8.0. Enzymatic activity in the washings or in the eluted fractions was measured using the artificial substrate, 4-methylumbelliferyl- $\beta$-galactoside (15).

\section{Western immunoblots}

Samples for SDS PAGE, including $\beta$-galactosidase-enriched preparations from human placenta $(13,14)$, smooth muscle cell extracts (4), fractions eluted from elastin and laminin affinity columns, and EBP affinity purified from sheep aorta (4), were dialyzed exhaustively against distilled water and concentrated by lyophilization. Samples were dissolved in SDS sample buffer containing DTT and separated by SDS-PAGE on $0.45-\mathrm{mm}$ thick, $12 \%$ gels (16). For Western immunoblot analysis, proteins were transferred to nitrocellulose at $100 \mathrm{~V}$ for $1 \mathrm{~h}$ $(17)$, and reacted with either the monoclonal antibody to the $67-\mathrm{kD}$ elastin-binding protein (anti-EBP) (12), with the antibody to $\beta$-galactosidase (anti-GAL) (13), or with affinity purified anti-S-GAL and anti-C-GAL polyclonal antibodies $(2 \mathrm{mg} / \mathrm{ml}$, diluted $1: 100)$. The reactions were visualized using peroxidase-conjugated GAM-HRP or GAR-HRP antibodies (diluted 1:100). Preimmune sera (diluted 1:5) were used as negative controls. For dot blot procedures, $1 \mu \mathrm{g}$ of human leukocyte elastase or porcine pancreatic elastase was dissolved in water and blotted onto nitrocellulose. The blots were reacted with the anti-SGAL antibody and visualized with GAR-HRP secondary antibody.

\section{Isolation and partial sequencing of elastin-binding protein from sheep aorta}

Aortas of adult sheep were minced, homogenized in $0.1 \mathrm{M}$ bicarbonate buffer, $\mathrm{pH} 8$, and extracted with $0.1 \mathrm{M}$ lactose in the same buffer containing proteinase inhibitors in the following final concentrations: 2 $\mathrm{mM}$ benzamidine, $2 \mathrm{mM} \epsilon$-amino caproic acid, $2 \mathrm{mM}$ PMSF, $1 \mathrm{mM}$ EDTA, and $1 \mathrm{mg} / \mathrm{ml}$ Trasylol. Extraction was overnight at $4^{\circ} \mathrm{C}$ with constant stirring and the remaining insoluble material was removed by centrifugation. The supernatant was dialyzed exhaustively $(12,000-$ $14,000 \mathrm{~mol}$ wt cut-off) at $4^{\circ} \mathrm{C}$ against $0.1 \mathrm{M}$ sodium bicarbonate, $\mathrm{pH} 8$, containing proteinase inhibitors. The elastin-binding protein in this extract was purified by elastin affinity chromatography, as described previously (4). The purity of the final product was confirmed by SDSPAGE. The region of the gel containing the protein band corresponding to $67 \mathrm{kD}$ was dissected, suspended in $70 \%$ formic acid containing $50 \mathrm{mg} / \mathrm{ml}$ cyanogen bromide, and incubated overnight at $20^{\circ} \mathrm{C}$. Cleavage products were separated by $\mathrm{C}-18$ reversed-phase HPLC and a major isolated peptide peak was sequenced by gas phase protein sequencing (Porton Instruments, Tarzana, CA).

\section{Binding of $67-k D$ form of $\beta$-galactosidase to elastin and laminin}

Kappa elastin or laminin from Engelbret Holm-Swarm tumor was immobilized on Affi-Gel $10(5 \mathrm{mg} / \mathrm{ml}$ and $2 \mathrm{mg} / \mathrm{ml}$ of resin, respectively) to prepare affinity columns as described previously $(4,5)$. Controls were Affi-Gel columns blocked with ethanolamine. Preparations of $\beta$-galactosidase from human placenta were dialyzed against $0.1 \mathrm{M}$

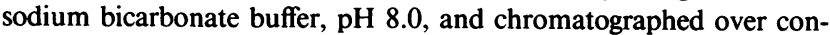
trol, elastin, or laminin affinity columns. Plasma membrane extracts of cultured aortic smooth muscle cells, prepared according to Wrenn et al. (2), was also chromatographed for comparison. Proteins bound to elastin or laminin were eluted with $0.1 \mathrm{M}$ lactose in $0.1 \mathrm{M}$ sodium bicarbonate buffer, $\mathrm{pH}$ 8.0, dialyzed against water, lyophilized, and analyzed by SDS-PAGE, followed by Western immunoblotting using anti-EBP, anti-GAL, anti-S-GAL, or anti-C-GAL antibody.
For dot blot procedures, tropoelastin, fibronectin, laminin, collagen I, and collagen III ( $4 \mu \mathrm{g}$ each) were blotted onto Immobilon P (Millipore Corp., Bedford, MA). After blocking with BSA and $0.01 \mathrm{M}$ Tween 20, blots were incubated either with the free S-GAL synthetic peptide $(1 \mathrm{mg} / \mathrm{ml})$ or with sheep EBP $(1 \mathrm{mg} / \mathrm{ml})$. Control blots were incubated with buffer only. Bound S-GAL peptide or EBP were then detected by incubation with antibody to the synthetic peptide (anti-SGAL) followed by HRP-conjugated secondary antibody. The identities of the ligands used in the dot blots were confirmed by incubation with antibodies specific to tropoelastin, fibronectin, laminin, collagen I, and collagen III, respectively, followed by HRP-conjugated secondary antibody. Anti-S-GAL did not react directly with any of these matrix proteins.

\section{Binding of the synthetic peptide to elastin and laminin}

Affinity columns made of S-GAL conjugated Ultrasyn D resin $(10 \mathrm{mg})$ (9) were incubated with either human plasma fibronectin $(30 \mu \mathrm{g} / \mathrm{ml})$, laminin from Engelbret Holm-Swarm tumor $(30 \mu \mathrm{g} / \mathrm{ml})$, or sheep tropoelastin $(30 \mu \mathrm{g} / \mathrm{ml})$ in $0.1 \mathrm{M}$ bicarbonate buffer, $\mathrm{pH} 7.4$, for $2 \mathrm{~h}$. The efficiency of protein binding was monitored by $\mathrm{OD}_{280}$ of the supernatants. The columns were washed with the same buffer until no protein was detected in the wash, then incubated for $5 \mathrm{~min}$ in SDS-PAGE sample buffer containing DTT. Proteins released from the resin were separated by SDS-PAGE and detected by silver staining and by Western immunoblotting using specific polyclonal antibodies to fibronectin, laminin, and tropoelastin $(5 \mathrm{mg} / \mathrm{ml}$ diluted 1:200).

In a separate series of experiments the columns made of S-GAL ( 10 $\mathrm{mg}$ ), fixed on Ultrasyn D resin (as described above) were incubated with affinity purified $\left[{ }^{3} \mathrm{H}\right]$ valine labeled sheep aorta tropoelastin $(20,000 \mathrm{cpm} / \mathrm{sample})(2)$ or with unlabeled laminin from Engelbret Holm-Swarm tumor $(30 \mu \mathrm{g} / \mathrm{ml})$ in $0.1 \mathrm{M}$ bicarbonate buffer, $\mathrm{pH} 7.4$, for $2 \mathrm{~h}$ in $4^{\circ} \mathrm{C}$. The resins were then washed with the same buffer until no protein was detected in the wash, eluted either with $10 \mathrm{mM}$ or 20 $\mathrm{mM}$ of free S-GAL synthetic oligopeptide, with $20 \mathrm{mM}$ of free C-GAL synthetic peptide or with $400 \mu \mathrm{g} / \mathrm{ml}$ of chondroitin sulfate, all dissolved in $0.1 \mathrm{M}$ bicarbonate buffer, $\mathrm{pH}$ 7.4. Blank Ultrasyn $\mathrm{D}$ resin with no peptide attached was also used as the control in each experiment. Proteins eluted from the S-GAL affinity columns were separated by SDS-PAGE and detected by autoradiography, by silver staining, and by Western immunoblots with specific antitropoelastin and antilaminin antibodies (see legends to Figs. 8 and 9 for details).

\section{Assay for elastase activity}

Elastolytic activity in sheep aorta EBP and human placental $\beta$-galactosidase preparations was assessed by incubation with $\left[{ }^{3} \mathrm{H}\right.$ ] elastin, as described previously (18). Human leukocyte elastase and bovine pancreatic elastases were used as positive controls.

\section{Results}

Immunoelectronmicroscopy using aortic tissue from 138 -d fetal lambs demonstrated that the polyclonal antibody to $\beta$-galactosidase (anti-GAL) localized not only to lysosomes, but also to the cell surface and to the extracellular elastic matrix, with a distribution similar to that seen for the antibody directed against EBP (Fig. 2, upper and middle panels). Moreover, a monospecific polyclonal antibody raised to the synthetic peptide, $N$-Ac-GSPSAQDASPL (anti-S-GAL), corresponding to a region in the sequence unique to the alternately spliced form of $\beta$-galactosidase, localized to the cell surface and to the elastic matrix. This antibody also localized to the endoplasmic reticulum and to secretory vesicles in these aortic cells, but not to lysosomes. Preabsorption of these antibodies with sheep aorta EBP immobilized on affinity columns abolished all immunogold staining (Fig. 2, lower panel), suggesting cross-reactivity rather than co-localization. In contrast, the pattern of immunogold staining with each of these antibodies was identical after 

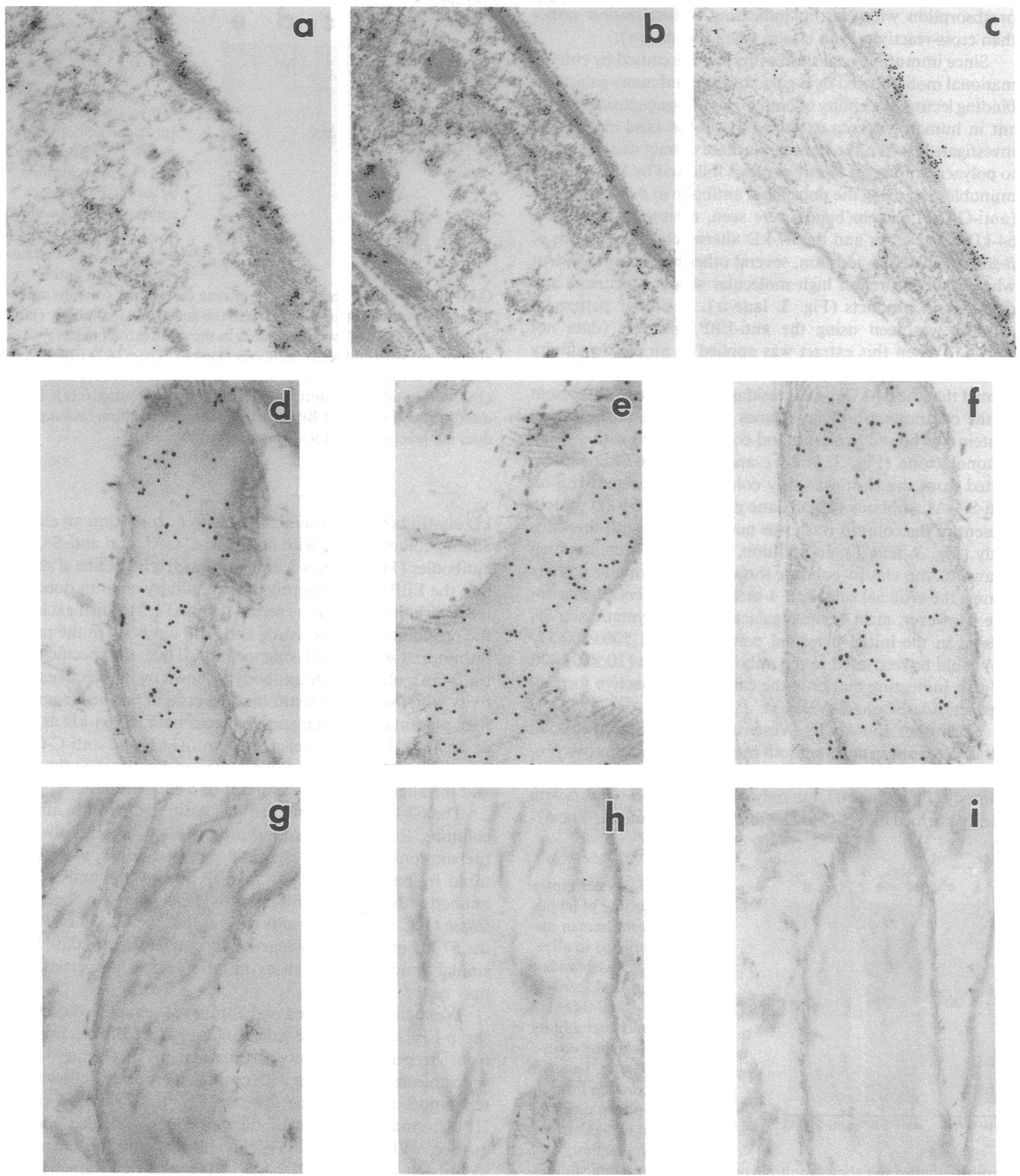

Figure 2. Representative immunoelectron photomicrographs of 138-d gestation fetal lamb aorta. Primary antibodies were: anti-EBP antibody to elastin-binding protein $(a, d, g)$, anti-GAL antibody to $\beta$-galactosidase $(b, e, h)$ and anti-S-GAL antibody to the synthetic peptide unique to the splice variant of $\beta$-galactosidase $(c, f, i)$. Secondary antibodies (goat anti-rabbit or goat anti-mouse) were labeled with 10-nm gold particles. (Upper panel) All antibodies localized to cell surfaces $(a, b$, and $c$ ). Magnification, 50,000. (Middle panel) All antibodies also localized to extracellular elastic fibers $(d, e$, and $f$ ). Magnification, 71,000 . (Lower panel) Preabsorption of all three antibodies with sheep aorta EBP immobilized on affinity columns ( $g, h$, and $i$, respectively) abolished all immunogold staining. Magnification, 71,000 . 
preabsorption with elastin, indicating co-localization rather than cross-reactivity with elastin (data not shown).

Since immunological similarities may be caused by conformational motifs shared by $\beta$-galactosidase and many galactosebinding lectins, the ability of both forms of $\beta$-galactosidase present in human placenta extracts $(13,14)$ to bind elastin was investigated. When the human placenta extract was subjected to polyacrylamide gel electrophoresis followed by Western immunoblotting using the polyclonal antibody to $\beta$-galactosidase (anti-GAL), protein bands were seen, corresponding to the 64-kD active form and the $67-\mathrm{kD}$ alternately spliced form of $\beta$-galactosidase. In addition, several other bands were evident which likely represent high molecular weight precursors and degradation products (Fig. 3, lane $a$ ). A similar pattern of staining was seen using the anti-EBP antibody (data not shown). When this extract was applied to an elastin affinity column, both anti-GAL and anti-EBP antibodies demonstrated that the $64-\mathrm{kD} \beta$-galactosidase protein was only present in the column wash (Fig. 3, lanes $b$ and $d$ ), and the 67-kD protein was bound to elastin and could be eluted with $\gamma$-D-galactonolactone (Fig. 3, lanes $c$ and $e$ ). The 67-kD protein eluted from the elastin affinity column also reacted with an anti-S-GAL antibody (Fig. 3, lane $g$ ), while the $64-\mathrm{kD}$ protein present in the column wash was not detectable with this antibody (Fig. 3, lane $f$ ). In addition, the $67-\mathrm{kD}$ protein which bound to the elastin column showed no enzymatic activity against the artificial substrate, 4 -methylumbelliferyl- $\beta$-galactoside. However, most of the $\beta$-galactosidase enzymatic activity present in the initial placental preparation $(11,500 \pm 500 \mathrm{U} /$ $\mathrm{ml})$ could be recovered in the unbound fraction $(10,850 \pm 400$ $\mathrm{U} / \mathrm{ml}$ ), indicating that only the catalytically inactive form of $\beta$-galactosidase bound to elastin.

We further showed by Western immunoblotting that an extract from sheep aorta smooth muscle cells contains two proteins, 67 and $64 \mathrm{kD}$, respectively, which react with anti-C-GAL antibody (Fig. 4, lane $a$ ), but only the 67-kD species reacts with affinity purified anti-S-GAL antibody (Fig. 4, lane $c$ ). The 67-

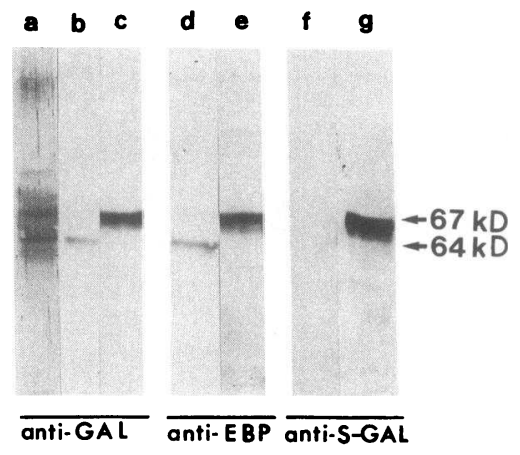

Figure 3. Western immunoblotting of preparation from human placenta enriched in all forms of $\beta$-galactosidase using anti-GAL, antiEBP, and anti-S-GAL before and after affinity chromatography on insoluble elastin. Lane $a$ is the preparation from human placenta rich in all forms of $\beta$-galactosidase before affinity

chromatography and shows multiple protein bands reacting with antibody to $\beta$-galactosidase (anti-GAL) including two at $67 \mathrm{kD}$ and 64 $\mathrm{kD}$ and other higher and lower molecular weight species which likely correspond to $\beta$-galactosidase precursor and degradation products (13). Unbound material washed from the elastin affinity column shows only a 64-kD species reacted with anti-GAL antibody (lane $b$ ) and with monoclonal anti-EBP (lane $d$ ). This species does not react with anti-S-GAL antibody (lane $f$ ). Bound material eluted from the elastin affinity column with $\gamma$-D-galactonolactone shows a 67-kD protein reacting with anti-GAL antibody (lane $c$ ), with anti-EBP (lane $e$ ), and with anti-S-GAL (lane $g$ ).

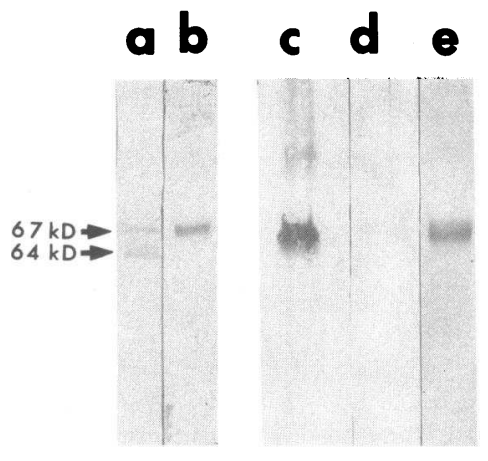

Figure 4. Western immunoblots show that anti-S-GAL antireacts specifically only with the $67-\mathrm{kD}$ splice variant of $\beta$-galactosidase present in the smooth muscle cell extract and with $67-\mathrm{kD}$ protein purified by an elastin affinity column, but not with a 64- $\mathrm{kD}$ active enzyme present in SMC extract reacting with anti-C.

GAL antibody. The aorta smooth muscle cell extract contains a $67-$ $\mathrm{kD}$ and $\mathrm{a} 64-\mathrm{kD}$ protein reacting with the anti-C-GAL antibody (lane a) but only the $67-\mathrm{kD}$ species present in the same extract reacts with affinity purified anti-S-GAL antibody (lane $c$ ). The 67-kD EBP eluted with lactose from an elastin affinity column reacts with both anti-CGAL and anti-S-GAL antibodies (lanes $b$ and $e$, respectively). Lane $d$ shows that the 67-kD EBP eluted from an elastin affinity column does not react with the preimmune serum diluted 1:5.

$\mathrm{kD}$ elastin binding protein eluted with lactose from an elastin affinity column reacts with both anti-C-GAL and anti-S-GAL antibodies (Fig. 4, lanes $b$ and $e$, respectively). Lane $d$ shows that the EBP eluted from the elastin affinity column does not react with the preimmune serum (diluted 1:5) which excludes the possibility of a preexisting anti-EBP antibody in the rabbit immunized with S-GAL oligopeptide. Thus, the specificity of the S-GAL oligopeptide antibody is shown by its selective reactivity with the $67-\mathrm{kD}$ elastin-binding protein purified from human placenta and sheep aorta whereas both the $64-\mathrm{kD}$ as well as the $67-\mathrm{kD}$ proteins react with anti-GAL and anti-C-GAL antibodies. The latter confirms a relationship between the EBP and the alternative spliced variant of $\beta$-galactosidase.

The $67-\mathrm{kD}$ protein isolated by elastin and laminin affinity columns, from extracts of cultured smooth muscle cells and preparations of human placental $\beta$-galactosidase, was recognized by both the antibody to EBP and by the anti-S-GAL antibody which reacts with the catalytically inactive $\beta$-galactosidase (Fig. 5). These results suggest that the 67-kD EBP and the $67-\mathrm{kD}$ enzymatically inactive form of $\beta$-galactosidase have similar functional as well as immunological properties and may be the same protein.

We therefore obtained and compared sequence data from sheep EBP and human $\beta$-galactosidase. The EBP was purified from sheep aorta by affinity chromatography on elastin (4) and was subjected to cleavage with cyanogen bromide, followed by separation of the peptide fragments by $\mathrm{C}-18$ reversed phase HPLC. Analysis of one of these fragments yielded the sequence, VVGGTEAQRNSWPL. This sequence showed a $50 \%$ identity to VVGSPSAQDEASPL, the predicted sequence for the unique region of the catalytically inactive $67-\mathrm{kD}$ form of human $\beta$-galactosidase produced by the frame shift (Fig. 1, lower panel). The sequence of sheep $\beta$-galactosidase has not been described. There was also a striking homology between the sequence, VVGGTEAQRNSWPL from EBP, and a sequence, VVGGTEAQRDSWPL, present at the $\mathrm{NH}_{2}$ terminus of the active form of porcine pancreatic and human leukocyte elastases (Fig. 1, lower panel) $(19,20)$. Furthermore, the antiS-GAL antibody also cross-reacted on dot blotting with both 


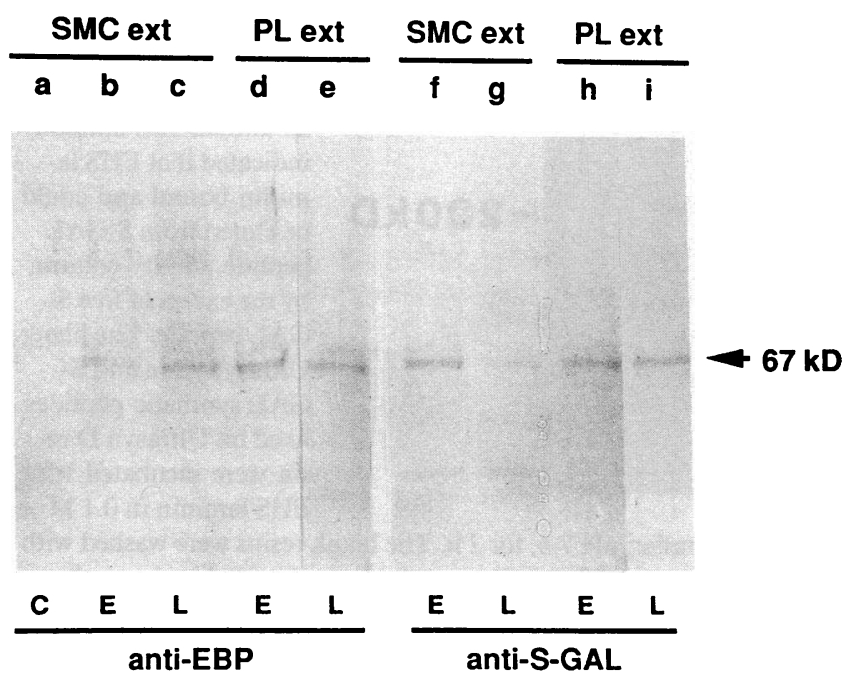

Figure 5. Western immunoblotting of a lactose extract of plasma membrane from cultured aortic smooth muscle cells (SMC ext, lanes $a, b, c, f$, and $g$ ) and $\beta$-galactosidase prepared from human placenta ( $P L$ ext, lanes $d, e, h$, and $i$ ). Both preparations were passed over affinity columns of elastin $(E)$, or laminin $(L)$, and bound proteins were eluted with lactose and separated by polyacrylamide gel electrophoresis. Bands were visualized using a monoclonal anti-EBP antibody, (lanes $a-e$ ) or a polyclonal anti-S-GAL antibody to a synthetic peptide unique to the splice variant of $\beta$-galactosidase (lanes $f-i$ ). A control column $(C)$ containing Affi-Gel only (lane $a$ ) did not retain any immunoreactive protein.

porcine pancreatic and human leukocyte elastases (data not shown). Moreover, these enzymes are lower molecular weight proteins and should not be confused with 67-kD EBP. In addition, neither sheep aorta EBP or human placental $\beta$-galactosidase preparations demonstrated any elastolytic activity. The homology does suggest that the sequence identified might represent a common elastin-binding motif on EBP and these elastolytic enzymes. The fact that only the $67-\mathrm{kD}$ catalytically inactive form of $\beta$-galactosidase bound to elastin further suggested that a sequence responsible for this property might be located in the 32 amino acid region predicted to be unique to the splice variant.

We therefore investigated the ligand-binding properties of the previously synthesized peptide, N-Ac-GSPSAQDEASPL (S-GAL), which is included in the sequence of interest. This peptide was shown on ligand blots to bind to immobilized elastin and laminin, but not to fibronectin, collagen I, or collagen III (Fig. 6). Anti-S-GAL antibody did not react directly with any of these matrix proteins.

Similarly, the S-GAL peptide immobilized on Ultrasyn-D resin used as an affinity column showed an ability to bind both elastin and laminin selectively but not fibronectin (Fig. 7). Moreover, affinity purified $\left[{ }^{3} \mathrm{H}\right]$ valine-labeled tropoelastin (Fig. 8) and EHS-laminin (Fig. 9) bound to the affinity columns made by S-GAL synthetic peptides fixed on Ultrasyn D resin, but not to the blank resin. Both ligands could be eluted from S-GAL peptide affinity columns by $10 \mathrm{mM}$ and $20 \mathrm{mM}$ of free S-GAL synthetic oligopeptide but not by $20 \mathrm{mM}$ of CGAL synthetic oligopeptide representing the $\mathrm{COOH}$-terminal sequence of $\beta$-galactosidase or by $400 \mu \mathrm{g} / \mathrm{ml}$ of chondroitin sulfate, all dissolved in $0.1 \mathrm{M}$ bicarbonate buffer, $\mathrm{pH}$ 7.4. The radioactive tropoelastin released from the S-GAL affinity resin

\section{Tropoelastin}

Fibronectin

Laminin

Collagen I

Collagen III

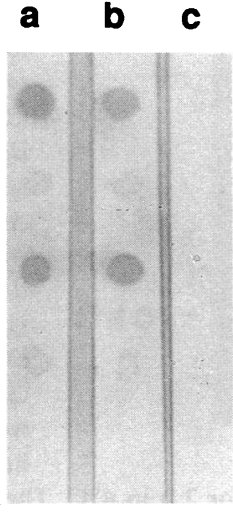

Figure 6. Tropoelastin and laminin (but not fibronectin, collagen I, and collagen III) bind to the synthetic peptide (S-GAL) corresponding to a region unique to the splice variant of $\beta$ galactosidase. Tropoelastin, fibronectin, laminin, collagen I, and collagen III were blotted onto Immobilon $\mathbf{P}$.

Blots were incubated with the S-GAL synthetic peptide (lane $a$ ) or with EBP (lane $b$ ). Lane $c$ was incubated with buffer alone. All blots were then incubated with the antibody to this synthetic peptide (anti-S-GAL) followed by HRP-conjugated secondary antibody.

was separated by SDS-PAGE and detected by autoradiography (Fig. 8), while laminin was separated by SDS-PAGE, transferred to nitrocellulose, and immunoblotted with specific antilaminin antibody (Fig. 9).

\section{Discussion}

Immunoelectronmicroscopy using fetal sheep aortic tissue showed localization of anti-GAL antibodies to smooth muscle cell surfaces and to the extracellular elastic matrix, with a distribution identical to that seen using antibodies to EBP, a 67-kD elastin- and laminin-binding galactolectin which is involved in the extracellular assembly of elastic fibers. This localization of antibody was not due to cross-reactivity with elastin itself. Although $\beta$-galactosidase is generally considered to be a $64-\mathrm{kD}$ lysosomal enzyme, Morreau et al. (8) described a product of alternate splicing of $\beta$-galactosidase mRNA which was catalytically inactive, which had a molecular weight of $\sim 67 \mathrm{kD}$, and which was not compartmentalized to lysosomes, and which, like the EBP, was secreted.

Our new anti-S-GAL antibody made to a synthetic oligopeptide corresponding to a sequence unique to this enzymatically inactive splice variant showed a similar immunolocalization to cell surfaces and extracellular elastic matrix as the antibody to EBP. Immunogold labeling with all three antibodies was abolished by preabsorption with EBP, suggesting crossreactivity. Moreover, Western blotting showed that antibodies

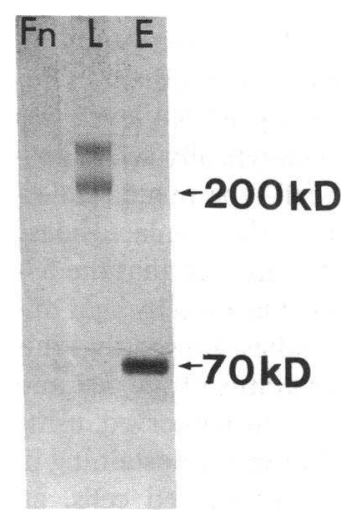

Figure 7. $70-\mathrm{kD}$ tropoelastin $(E)$ and 220- and 240-kD laminin $(L)$ but not fibronectin $(F n)$ bound to the S-GAL affinity resin. Three S-GAL peptide affinity columns (S-GAL peptides immobilized on Ultrasyn D resin) were incubated with human plasma fibronectin, EHS-laminin, or bovine tropoelastin. After extensive washing, the bound proteins released from the resins by 5 min incubation with SDS-sample buffer were analyzed by SDS gel electrophoresis followed by Western immunoblotting with polyclonal antibodies to fibronectin, laminin, and tropoelastin followed by HRP-conjugated secondary antibody. 


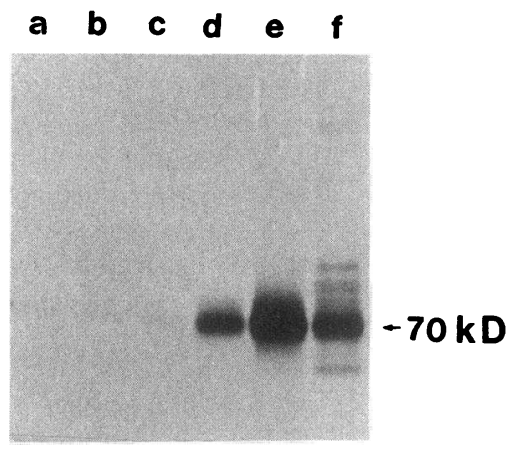
with $0.1 \mathrm{M}$ bicarbonate buffer until no protein was detected in the wash, then eluted with different reagents as mentioned below. The blank resin was eluted with $20 \mathrm{mM}$ of synthetic S-GAL peptides (lane $a$ ). The S-GAL peptide containing resin was subsequently eluted first with $20 \mathrm{mM}$ of free C-GAL synthetic peptides (lane $b$ ), then with $400 \mu \mathrm{g} / \mathrm{ml}$ of chondroitin sulfate (lane $c$ ), and finally with $10 \mathrm{mM}$ of free S-GAL synthetic peptides (lane $d$ ). Each 15-min elution was followed by $15 \mathrm{~min}$ wash of the column with the $0.1 \mathrm{M}$ bicarbonate buffer. Only free S-GAL peptide eluted tropoelastin from the S-GAL affinity resin (lane $d$ ). Radioactive tropoelastin absorbed by another affinity column containing immobilized S-GAL peptides was directly eluted by $20 \mathrm{mM} \mathrm{S}-\mathrm{GAL}$ free peptide (lane $e$ ). Lane $f$ shows that tropoelastin absorbed by the S-GAL peptide affinity resin can also be released by boiling the resin in SDS-sample buffer. In this case, however, numerous protein bands (other than $70 \mathrm{kD}$ ) can be detected due to temperature dependent coacervation and degradation of tropoelastin. All these radiolabeled bands were reactive with a monospecific antitropoelastin antibody on the Western blot (data not shown).

raised to $\beta$-galactosidase (anti-GAL), to its $\mathrm{COOH}$-terminal sequence (anti-C-GAL) and anti-S-GAL antibody made to a synthetic peptide corresponding to a sequence unique to splice variant of $\beta$-galactosidase (but not its preimmune serum) recognized EBP purified from sheep aorta, and antibodies to EBP recognized multiple forms of human placental $\beta$-galactosidase. Together, these data clearly demonstrated immunological similarity between $\beta$-galactosidase and EBP. It is noteworthy, however, that anti-S-GAL antibody did not recognize a $64-\mathrm{kD}$ active form of the enzyme present in the placental or smooth muscle cell extracts and detected in the unbound fraction from an elastin affinity columns. This not only confirmed the specificity of the anti-S-GAL antibody but strongly suggested a shared sequence, if not identity, between the EBP and 67-kD spliced variant of $\beta$-galactosidase.

In our study in both placental and aorta smooth muscle cell extracts, we found roughly equivalent amounts of the $67-\mathrm{kD}$ and $64-\mathrm{kD}$ proteins expressed, whereas, in the study of Morreau et al. (8), the expression of the $67-\mathrm{kD}$ protein in human fibroblasts and COS- 1 cells as judged by mRNA levels was predicted at $\sim 1: 10$ that of the $64-\mathrm{kD}$ catalytically active protein. The discrepancy may be due to cell-type related differences in posttranscriptional regulation of the $\beta$-galactosidase mRNAs. In addition, Morreau et al. (8) reported that the 67$\mathrm{kD}$ protein was perinuclear in immunolocalization by light microscopy, whereas our ultrastructural studies showed that this protein was present in the secretory apparatus of the cell and especially on the cell membrane. We have also observed, using light microscopy, that there is perinuclear immunostaining in permeabilized cells, whereas in nonpermeabilized cells, all a b c d e f

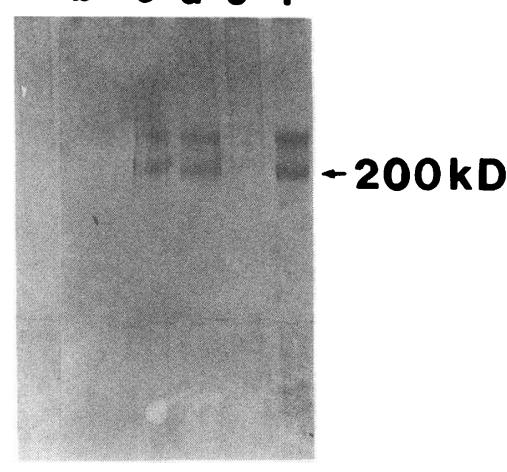

Figure 9. SDS-PAGE followed by Western immunoblotting with an antilaminin antibody indicated that EHS laminin bound and could be eluted from S-GAL peptide affinity column by the excess of free $S$ GAL peptide. The blank Ultrasyn resin and SGAL synthetic peptides fixed on Ultrasyn D resin were incubated with EHS laminin in $0.1 \mathrm{M}$

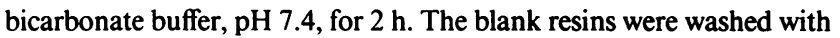
$0.1 \mathrm{M}$ bicarbonate buffer until no protein was detected in the wash, then eluted with $20 \mathrm{mM}$ of synthetic S-GAL oligopeptide (lane $a$ ). The S-GAL peptide containing resins were washed with the same buffer until no protein was detected in the wash, then eluted with 20 $\mathrm{mM}$ of C-GAL synthetic oligopeptide (lane $b$ ). Then, after a 15-min wash in bicarbonate buffer, the same column was eluted with $10 \mathrm{mM}$ of synthetic S-GAL oligopeptide (lane $c$ ). A separate S-GAL affinity column which absorbed laminin was also eluted with $20 \mathrm{mM} \mathrm{S}-\mathrm{GAL}$ peptide (lane $d$ ). Lane $e$ shows that elution of the S-GAL affinity column with $400 \mu \mathrm{g} / \mathrm{ml}$ of chondroitin sulfate did not released any bound laminin. The laminin bound to this column could subsequently be eluted with $20 \mathrm{mM}$ of free S-GAL peptides (lane $f$ ).

three antibodies (anti-GAL, anti-EBP, and anti S-GAL) localized the 67-kD protein on the cell surfaces (data not shown).

The 67-kD EBP binds to VGVAPG sequences on elastin and to LGTIPG hydrophobic sequences on laminin. However, dissociation of elastin and laminin from the EBP can also be induced with galactose-containing sugars (1-5). Affinity chromatography of human placenta extract enriched in all forms of $\beta$-galactosidase on immobilized elastin and laminin demonstrated that only the $67-\mathrm{kD}$ protein was bound to these affinity columns and that, like EBP, this protein could be eluted by lactose or $\gamma$-D-galactonolactone. Furthermore, this elastinbound, $67-\mathrm{kD}$ protein which was recognized by antibodies to $\beta$-galactosidase (anti-GAL and anti-C-GAL), by an anti-EBP antibody, and additionally by an anti-S-GAL antibody raised to the peptide representing the unique sequence present only in the splice variant of $\beta$-galactosidase had no enzymatic activity, although such activity was present in the unbound fraction. Thus, in addition to a similar molecular weight and immunological cross-reactivity, this enzymatically inactive form of $\beta$ galactosidase also shows elastin- and laminin-binding properties which are identical to those of EBP.

Partial sequence data obtained from cyanogen bromidegenerated peptides from sheep EBP showed a 50\% identity with a sequence from the splice variant of human $\beta$-galactosidase. Further studies in our laboratory to obtain further sequence data from human pulmonary artery EBP or sheep placental $\beta$-galactosidase have, to date, proven unsuccessful. We were able, however, to show that N-Ac-GSPSAQDEASPL synthetic oligopeptide (S-GAL) which includes the sequence corresponding to a region unique to the splice variant of $\beta$-galactosidase binds to immobilized elastin and laminin, but not to fibronectin, collagen I, or collagen III. Similarly, the S-GAL peptide immobilized on Ultrasyn-D resin used as an affinity column showed an ability to bind both elastin and laminin selectively but not fibronectin. Specificity of this binding was confirmed 
by the fact that both bound ligands could be eluted from SGAL affinity columns by an excess of free S-GAL peptides but not by the unrelated peptide (C-GAL) or by chondroitin sulfate. The latter observation further indicates that elastin/laminin and galactosugar binding sites on the EBP are different.

In addition, there were striking homologies among this EBP sequence, the sequence unique to the $\beta$-galactosidase splice variant which demonstrated elastin/laminin-binding properties, and a sequence present at the $\mathrm{NH}_{2}$ terminus of the active form of both porcine pancreatic elastase and human leukocyte elastase. This homology may not be altogether surprising since elastases must also bind elastin in order to cleave the protein. Although the three-dimensional structures of at least some elastases are well known (21), the role of this $\mathrm{NH}_{2}$-terminal sequence is not clear. Specifically, there appears to be little previous evidence that it might be involved in the association of elastin with the enzyme. Indeed, homologous sequences are also found at the $\mathrm{NH}_{2}$ termini of a wide variety of other serine proteases $(22,23)$, most of which do not cleave insoluble elastin but do, however, digest tropoelastin. Thus, our observations of the ability of this peptide to bind to elastin and laminin indicates that the functional significance of this sequence in elastases deserves further investigation and might provide new information useful in addressing the function and mechanism of inhibition of these proteinases.

Taken together, these data strongly suggest that the EBP previously identified on the surface of cells and implicated in the assembly of the extracellular elastic matrix is related to an alternately spliced form of $\beta$-galactosidase which has lost its catalytic activity and lysosomal targeting but has retained its ability to bind galactosugars and has acquired a sequence allowing it to recognize and bind elastin and laminin. This would represent an unusual biological mechanism for the generation of functional diversity from an ancestral protein. The concept of underlying evolutionary relationships between proteins of diverse function has gained strength as more protein sequence data have emerged (22). In this regard, the relationship between the elastin-binding protein and the alternately spliced form of $\beta$-galactosidase may be a particularly good example of the resourcefulness and parsimony of nature.

\section{Acknowledgments}

This work was supported by grants from the Heart and Stroke Foundation of Ontario (T1514, T1679, and B2040) and from the Medical Research Council of Canada (MT10427, MT8546).

\section{References}

1. Hinek, A., D. S. Wrenn, R. P. Mecham, and S. H. Barondes. 1988. The elastin receptor: a galactoside-binding protein. Science (Wash. DC). 239:15391541 .

2. Wrenn, D. S., A. Hinek, and R. P. Mecham. 1988. Kinetics of receptor mediated binding of tropoelastin to ligament fibroblasts. J. Biol. Chem. 238:2280-2284.
3. Mecham, R. P., A. Hinek, R. Entwistle, D. S. Wrenn, G. L. Griffin, and R. M. Senior. 1989. Elastin binds to a multifunctional $67 \mathrm{kD}$ peripheral membrane protein. Biochemistry. 28:3716-3722.

4. Hinek, A., R. P. Mecham, F. W. Keeley, and M. Rabinovitch. 1991. Impaired elastin fiber assembly related to reduced $67-\mathrm{kD}$ elastin-binding protein in fetal lamb ductus arteriosus and in cultured aortic smooth muscle cells treated with chondroitin sulfate. J. Clin. Invest. 88:2083-2094.

5. Mecham, R. P., A. Hinek, G. L. Griffin, R. M. Senior, and L. R. Liotta 1989. $67 \mathrm{kD}$ elastin binding protein is homologous to the tumor cell $67 \mathrm{kD}$ laminin receptor. J. Biol. Chem. 264:16652-16657.

6. Mecham, R. P., L. Whitehouse, M. Hay, A. Hinek, and M. P. Sheetz. 1991 Ligand affinity of $67 \mathrm{kD}$ elastin/laminin binding protein is modulated by the protein's lectin domain: visualization of elastin/laminin-receptor complexes with gold-tagged ligands. J. Cell Biol. 113:187-194.

7. O'Brien, J. S. 1989. In The metabolic Basis of Inherited Disease. C. R. Scriver, A. L. Beaudet, W. C. Sly, and D. Valle, editors. McGraw-Hill Inc., New York. 1797-1806.

8. Morreau, H. N., N. J. Galjart, N. Gillemans, R. Willemsen, G. T. J. van der Horst, and A. d'Azzo. 1989. Alternative splicing of $\beta$-Galactosidase mRNA generates the classic lysosomal enzyme and a related protein $\beta$-Galactosidase. J. Biol. Chem. 264:20655-20663.

9. Sutliffe, J. G., F. M. Shinnick, N. Green, F. T. Liu, H. L. Niman, and R. A. Lerner. 1980. Chemical synthesis of polypeptide predicted from nucleotide sequence allows detection of new retroviral gene product. Nature (Lond.). 287:801-805.

10. Mayer, R. J., and J. H. Walker. 1987. Polyclonal antiserum production and processing. In Immunochemical Methods in Cell and Molecular Biology. Biological Techniques Series. Academic Press, New York. 4-38.

11. Callawn, J., and Y. Paterson. 1990. In Current Protocols in Molecular Biology. F. M. Ansubel, R. Brent, R. Kingston, D. D. Moore, J. G. Seidman, J. A. Smith and K. Struhl, editors. Green Publishing Association and Wiley-Interscience, J. Wiley and Sons, New York. 11.15.1.

12. Mecham, R. P., A. Hinek, E. G. Cleary, U. Kucich, and J. Rosenbloom. 1988. Development of immunoreagents to ciliary zonules that react with protein components of elastic fibers. Biochem. Biophys. Res. Commun. 151:822-826.

13. Hubbes, M., R. M. D’Agrosa, and J. W. Callahan. 1992. Human placental $\beta$-galactosidase: characterization of the dimer and complex forms of the enzyme. Biochem. J. 285:827-831.

14. D'Agrosa, R. M., M. Hubbes, S. Zhang, R. Shankaran, and J. W. Callahan. 1992. Characteristics of the $\beta$-galactosidase-carboxypeptidase complex in

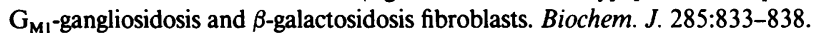

15. Jones, C. S., D. Mahuran, J. A. Lowden, and J. W. Callahan. 1984. Human placental $\beta$-galactosidase: structural and immunological observations. Can. J. Biochem. Cell Biol. 64:529-534.

16. Laemmli, U. K. 1970. Cleavage of structural proteins during the assembly of the head of bacteriophage $\mathrm{T}_{4}$. Nature (Lond.). 227:680-685.

17. Towbin, H., T. Staehlin, and J. Gordon. 1979. Electrophoretic transfer of proteins from an acrylamide gel to nitrocellulose: procedures and some applications. Proc. Natl. Acad. Sci. USA. 76:4350-4354.

18. LaBourene, J. I., J. G. Coles, D. J. Johnson, A. Mehra, M. Rabinovitch, and F. W. Keeley. 1990. Alterations in elastin and collagen related to the mechanism of progressive venous obstruction in a piglet model. Circ. Res. 66:438-456.

19. Shotton, D. M., and B. S. Hartley. 1970. Amino-acid sequence of porcine pancreatic elastase and its homologies with other serine proteinases. Nature (Lond.). 225:802-804.

20. Sinha, S., W. Watorek, S. Karr, J. Giles, W. Bode, and J. Travis. 1987. Primary structure of human neutrophil elastase. Proc. Natl. Acad. Sci. USA 84:2228-2232.

21. McKenzie, H. A., and F. H. White. 1991. In Advances in Protein Chemistry. C. B. Anfinsen, J. T. Edsall, F. M. Richards, and D. S. Eisenberg, editors. Plenum Publishing Corp., New York. 41:173-315.

22. Doolittle, R. F., and D. F. Feng. 1987. Reconstructing the evolution of vertebrate blood coagulation from a consideration of the aminoacid sequences of clotting proteins. In Cold Spring Harbor Symposia on Quantitative Biology. 52:869-874.

23. Doolittle, R. F. 1989. Similar amino acid sequences revisited. Trends Biochem. Sci. 14:244-245. 